${ }^{1}$ WM Ricketts, ${ }^{2}$ LF Anderson, ${ }^{1}$ VLC White; ${ }^{1}$ Barts Health NHS Trust, London, UK; ${ }^{2}$ Public Health England, London, UK

\subsection{6/thoraxjn-2013-204457.243}

Introduction The London Borough of Newham consistently has the highest incidence of tuberculosis $(\mathrm{TB})$ in the UK $(\approx 120$ / $100,000)$, with case numbers continuing to rise. We sought to investigate social risk factors for $\mathrm{TB}$ as compared with the general population in this borough.

Methods Of 242 adult patients diagnosed with TB in 2012 at the Newham Chest Clinic $170(70.3 \%)$ completed a structured interview assessing for social risk factors. Demographic data was obtained from hospital records. TB case data was compared with 2011 census data using Fisher's exact test or t-tests as appropriate.

Results Data directly comparable to 2011 census data is summarised in Table 1. Cases had a mean of 3.43 (95\% CI 3.07$3.8)$ household contacts, 2.28 (1.41-3.16) non-household family contacts and $2.02(1.71-2.33)$ close friends. Household and family contacts were almost exclusively of the same ethnicity as the

\begin{tabular}{|c|c|c|c|}
\hline Demographic Factor & $\begin{array}{l}\text { TB Cases } \\
\text { (total 170) }\end{array}$ & $\begin{array}{l}\text { Census data } \\
\text { (total } 307,984 \text {, unless } \\
\text { stated otherwise) }\end{array}$ & Significance \\
\hline $\begin{array}{l}\text { Mean age } \\
\text { (under } 16 \text { 's excluded) }\end{array}$ & $\begin{array}{l}32.9(95 \% \mathrm{Cl} \\
31.12-34.68)\end{array}$ & $\begin{array}{l}38.4(95 \% \mathrm{Cl} \\
38.31-38.45) \\
\mathrm{n}=238,090\end{array}$ & $p<0.0001$ \\
\hline $\begin{array}{l}\text { Gender } \\
\text { - Male } \\
\text { - Female }\end{array}$ & $\begin{array}{l}\cdot 102(60 \%) \\
\cdot 68(40 \%)\end{array}$ & $\begin{array}{l}\cdot 160,336(52.1 \%) \\
\cdot 147,648(47.9 \%)\end{array}$ & $p=0.04557$ \\
\hline Mean household size & $\begin{array}{l}4.43(95 \% \mathrm{Cl} \\
4.07-4.8)\end{array}$ & $\begin{array}{l}2.99(95 \% \mathrm{Cl} \\
2.98-3.01) \\
\mathrm{n}=101,519\end{array}$ & $P<0.0001$ \\
\hline Country/Region of Birth & $\cdot 66(38.8 \%)$ & $\cdot 26,807(8.7 \%)$ & $P<0.0001$ \\
\hline - India & $\cdot 28(16.5 \%)$ & $\cdot 16,462(5.4 \%)$ & $P<0.0001$ \\
\hline Pakistan & $\cdot 24(14.1 \%)$ & $\cdot 20,945(6.8 \%)$ & $P=0.0006$ \\
\hline - Bangladesh & $\cdot 16(9.4 \%)$ & $\cdot 30,822(10 \%)$ & ND \\
\hline - Africa & $\cdot 13(7.7 \%)$ & $\cdot 142,570(46.3 \%)$ & $P<0.0001$ \\
\hline $\begin{array}{l}\cdot \text { UK } \\
\cdot \text { Europe }\end{array}$ & $.6(3.5 \%)$ & $\cdot 32,893(10.7 \%)$ & $\mathrm{P}=0.0011$ \\
\hline $\begin{array}{l}\text { Period in UK (years) } \\
\text { (excluding UK born) }\end{array}$ & $\begin{array}{l}\cdot 25(15.9 \%) \\
\cdot 66(42 \%)\end{array}$ & $\begin{array}{l}\cdot 27,353(16.5 \%) \\
\cdot 30,140(18.2 \%)\end{array}$ & $\begin{array}{l}\text { ND } \\
p<0.0001\end{array}$ \\
\hline $\begin{array}{l}\cdot<2 \\
\cdot 2-<5\end{array}$ & $\begin{array}{l}\cdot 34(21.7 \%) \\
\cdot 32(20.4 \%)\end{array}$ & $\begin{array}{l}\cdot 36,634(22.1 \%) \\
\cdot 71,287(43.1 \%)\end{array}$ & $\begin{array}{l}\text { ND } \\
p<0.0001\end{array}$ \\
\hline $\begin{array}{l}\cdot 5-<10 \\
\cdot>10\end{array}$ & & & \\
\hline Ethnicity & . $141(82.9 \%)$ & $\cdot 120,846(39.2 \%)$ & $P<0.0001$ \\
\hline - South-Asian & $\cdot 14(8.2 \%)$ & . $40,659(13.2 \%)$ & $P=0.0542$ \\
\hline $\begin{array}{l}\text { Black African } \\
\text { White UK }\end{array}$ & $\cdot 1(0.6 \%)$ & $\cdot 52,207(17 \%)$ & $P<0.0001$ \\
\hline Social Grade & $\cdot 169$ & $\cdot 87,908$ & $\cdot N / A$ \\
\hline Total & $\cdot 15(8.9 \%)$ & $\cdot 14,541(16.5 \%)$ & $\cdot P=0.0066$ \\
\hline$\cdot A B$ & $54(32 \%)$ & $\cdot 26,271(29.9 \%)$ & $\cdot \mathrm{ND}$ \\
\hline$\cdot \mathrm{C} 1$ & $\cdot 13(8 \%)$ & $\cdot 16,240(18.5 \%)$ & $P=0.0001$ \\
\hline$\cdot \mathrm{C} 2$ & $.87(51.8 \%)$ & $\cdot 30,856(35.1 \%)$ & $P<0.0001$ \\
\hline - DE & & & \\
\hline $\begin{array}{l}\text { Demographic and social ris } \\
\text { ulation of the borough fron } \\
\text { the "Household Reference } \\
B=\text { Middle management, } \\
\text { ual workers, D = Unskilled }\end{array}$ & $\begin{array}{l}\text { ictors for TB cas } \\
\text { e } 2011 \text { census } \\
\text { son" as follows } \\
=\text { Junior manage } \\
\text { nual and casual }\end{array}$ & $\begin{array}{l}\text { in Newham compared to } t \\
\text { ta. Social grade is based } \\
A=\text { Professional and high } \\
\text { ent and administrative, } C 2 \\
\text { orkers and } \mathrm{E}=\text { Unemploye }\end{array}$ & $\begin{array}{l}\text { general pop- } \\
\text { on the job of } \\
\text { management, } \\
\text { Skilled man- }\end{array}$ \\
\hline
\end{tabular}

cases, but with $18.4 \%$ of household contacts and $49.2 \%$ of family contacts being UK born, compared with $7.7 \%$ of cases. The majority of friends were of the same ethnicity (86\%) with 18.4\% UK born, $89.4 \%$ of cases had no close friends from a different ethnic group. None of the cohort reported alcohol or drug abuse or had been in prison in the last 5 years, one was currently homeless. Fifteen (8.8\%) reported recent visitors from abroad and 61 (38.9\% of foreign born) reported returning to their country of birth for greater than three weeks, with $75.4 \%$ having returned within the last two years, a further eleven had travelled to a high incidence country in the last ten years, six of whom were UK born travelling to their parents' country of birth. Conclusions In this high incidence area of an otherwise low incidence country TB is significantly more common in those of South-Asian birth and ethnicity. It is more common in young adults who have lived in the UK between two and five years and work in unskilled jobs or are unemployed. This picture is likely driven by $\mathrm{TB}$ reactivation in new immigrants accompanied by a lack of social mixing and suggesting the influence of relative poverty in the development of TB.

\section{P94 RETROSPECTIVE STUDY TO ASSESS THE BACKGROUND INCIDENCE OF HEPATITIS B AND C IN PATIENTS WITH TUBERCULOSIS AND LATENT TUBERCULOSIS AT WHIPPS CROSS HOSPITAL}

VE Beasley, R Anders, M Darmalingam; Whipps Cross University Hospital, London, United Kingdom

\subsection{6/thoraxjn|-2013-204457.244}

Since 2010 our hospital has aimed to test all new patients diagnosed with tuberculosis $(\mathrm{TB})$ or latent $\mathrm{TB}$ for hepatitis $\mathrm{B}$ and C. Guidelines from the NICE recommend all new patients with TB should be tested for HIV. However, no such guidelines exist regarding hepatitis $\mathrm{B}$ and $\mathrm{C}$ screening. We feel patients with undiagnosed hepatitis $\mathrm{B}$ and $\mathrm{C}$ should be identified prior to commencing anti-TB medication due to the potential risk of severe hepatotoxicity. Recently within London, anecdotally two patients with undiagnosed hepatitis treated for $\mathrm{TB}$, subsequently required liver transplantation as a result of significant hepatotoxicity. A retrospective study was conducted to assess hepatitis $\mathrm{B}$ and $\mathrm{C}$ incidence within patients treated for $\mathrm{TB}$ and latent $\mathrm{TB}$ during 2012. Blood results were reviewed for any new hepatitis $B / C$ results. Table 1 shows these results, highlighting that $4.7 \%$ of patients screened in both cohorts tested positive for Hepatitis B or C.

The two additional hospitals within the trust contribute a large number of additional $\mathrm{TB}$ and latent $\mathrm{TB}$ patients, totalling 1115 patients. Through extending the earlier observation of 4.7\% Hepatitis B or C incidence in our hospital, there would be an estimated 51 patients affected across the trust.

Abstract P94 Table 1. Results of TB patients screened positive for hepatitis.

\begin{tabular}{lllll}
\hline & $\begin{array}{l}\text { Total number } \\
\text { of patients } \\
\text { diagnosed } \\
\text { wype }\end{array}$ & $\begin{array}{l}\text { Number of } \\
\text { patients } \\
\text { screened }\end{array}$ & Positive screening result \\
\cline { 4 - 5 } & for hepatitis & Hepatitis B & Hepatitis C \\
\hline Active TB & 153 & 143 & 2 & 6 \\
Latent TB & 59 & 49 & 1 & 0 \\
\hline
\end{tabular}


Based on the individual costs of screening tests for Hepatitis B (£6.30) and C (£5.13), for the 1115 current TB patients, our trust wide hepatitis screening costs were estimated at $£ 12,744$. The approximate cost of a liver transplant operation at Kings College Hospital in 2012 was $£ 125,000$, not including the additional after care costs and accounting for possible complications. We feel the cost of hepatitis screening is outweighed by the benefits of identifying patients with positive serology in a timely fashion; permitting closer monitoring of their liver function and initiating an early gastroenterology referral.

It is vital we attempt to reduce the morbidity and possible mortality of hepatotoxicity in hepatitis positive TB patients; the financial, emotional and psychological implications for a patient undergoing a liver transplant are enormous. We propose that hepatitis screening is incorporated into current TB guidelines.

\section{P95 WHY HAVE TB NOTIFICATIONS DECREASED BY $50 \%$ IN FOUR YEARS, IN A RURAL DISTRICT OF ZIMBABWE?}

${ }^{1} \mathrm{HE}$ Patrick, ${ }^{2} \mathrm{E}$ Manomano, ${ }^{2} \mathrm{~S}$ Sah, ${ }^{3} \mathrm{~N}$ Kwenzakwenkosi, ${ }^{3} \mathrm{C}$ Mushore, ${ }^{4} \mathrm{RD}$ Barker; ${ }^{1}$ National Institute for Health and Clinical Excellence, London, UK; ${ }^{2} T B$ Alert, Brighton, UK; ${ }^{3}$ Department of Health and Child Welfare, Manicaland Province, Zimbabwe; ${ }^{4}$ King's Health Partners, London, UK

\subsection{6/thoraxjnl-2013-204457.245}

Introduction Annual TB notifications in Buhera District, Manicaland, peaked at 1,665 in 2008 and fell to 866 in 2012. The fall in TB notifications is disproportionate to national trends. ${ }^{1}$ We considered three possible reasons for the fall in TB incidence; a real reduction related to improved health of the population, an apparent reduction due to failure to identify or register new cases, and an apparent reduction due to fewer patients coming from outside the district to use relatively high quality services. We analysed existing data and planned further exploration.

Methods We used the district's electronic TB database maintained by the charity TB Alert. We also accessed data relating to a recent pilot of the use of GeneXpert in the District. We planned further analyses to explore within district variation in notifications. We planned interviews with $\mathrm{TB}$ coordinators, primary care, hospital staff and senior staff from within and outside the province.

Results The district TB register appeared complete. Treatment success rates increased from 2006 (55\%) but stabilised at 65$70 \%$. The proportion of TB patients who died peaked at $20 \%$ in 2006 and reduced to $10.5 \%$ in 2011 possibly due to changes in case ascertainment. Re-treatment cases increased from $2 \%$ in 2007 to $8.5 \%$ in 2012. Use of the GeneXpert machine identified 1 case of multi-drug resistant TB in 2008, increasing to 29 cases in 2012. The proportion of TB patients coming from outside the district seeking services appears to be constant, but high, at $22 \%$ in 2008 and $23 \%$ in 2012.

Conclusions Initial analyses suggest that $\mathrm{TB}$ documentation in the district is well maintained. ${ }^{2}$ However there are significant changes in the local epidemiology of TB and the dramatic fall in the local incidence of tuberculosis is not completely explained. Further exploration of local TB documentation and practice associated with consultation with national and international TB experts should help to clarify the situation.

\section{REFERENCES}

1. World Health Organisation. Global Tuberculosis Report, 2012. http://www.who.int/ tb/publications/global_report/gtbr12_annex2.pdf
2. Scott KM, Millard FJC, Smith RM, Manomano E, Glenshaw M, Barker RD. Five years of support for a tuberculosis programme in rural Zimbabwe: What has been achieved? Thorax 2009;64 (Suppl IV):A11

\section{P96 CHARACTERISTICS AND OUTCOMES OF MULTI-DRUG RESISTANT TUBERCULOSIS PATIENTS IN A MAJOR URBAN CENTRE IN THE UK}

${ }^{1} \mathrm{GC}$ Hagan, ${ }^{2} \mathrm{~F}$ Edwards, ${ }^{1} \mathrm{~J}$ Nation, ${ }^{3} \mathrm{H}$ Kunst, ${ }^{3} \mathrm{M}$ Dedicoat, ${ }^{1} \mathrm{~N}$ Nathani; ${ }^{1}$ City Hospital, Birmingham, United Kingdom; ${ }^{2}$ Medical School, University of Birmingham, Birmingham, United Kingdom; ${ }^{3}$ Birmingham Chest Clinic, Heart of England NHS Foundation Trust, Birmingham, United Kingdom

\subsection{6/thoraxjn-2013-204457.246}

Introduction and objectives Multi-drug resistant tuberculosis (MDR-TB), defined as TB resistant to rifampicin and isoniazid is an expanding problem. $1.6 \%$ of TB isolates in the UK are MDR$\mathrm{TB}$, but rates are higher in some parts of the world. Treatment is usually 20-24 months and frequently associated with significant side effects. In our city, MDR-TB is mostly managed in two main hospitals. We sought to examine the characteristics and outcomes of our MDR-TB patients. Methods

Patients from $1^{\text {st }}$ Jan 2008 from one institution and $1^{\text {st }}$ Jan 2009 from the other institution were included with a cutoff period of $1^{\text {st }}$ May 2013 and follow up to $1^{\text {st }}$ June 2013. Data was gathered from case note review and enhanced tuberculosis surveillance data.

Results 31 patients were identified; demographics are shown in table 1. Site of TB was pulmonary in $18(58 \%)$ patients, lymph node in $10(32 \%)$, soft tissue in $2(6 \%)$, and intra-cerebral in 1 (3\%). 10(32\%) patients were on standard anti TB treatment at time of diagnosis. 22(71\%) patients developed side effects of treatment; these included ototoxicity (7 patients), gastrointestinal side effects (4 patients), hypothyroidism due to para-aminosalicylic acid or prothionamide (2 patients) and neuropsychiatric side effects from cycloserine (2 patients). 9(29\%) patients underwent a surgical procedure; 7 for diagnosis and 2 to assist treatment (both lobectomies). Treatment was ongoing in 14(45\%) patients and $11(35 \%)$ patients had completed treatment by the cutoff period. $4(12 \%)$ patients defaulted and 2 patients were transferred out during treatment (1 overseas, 1 to another UK centre).

Conclusions The lack of MDR-TB risk factors in a proportion of patients underscores the importance of trying to obtain microbiological samples and utilisation of resistance mutation analysis. Side effects are frequent and treatment should be undertaken by physicians with expertise. The BTS MDR-TB service plays a valuable role in management of these complex patients.

\begin{tabular}{ll} 
Abstract P96 Table 1. & \\
\hline No. Male & $22(67 \%)$ \\
Mean age (Median +/- IQR years) & $29(+/-11)$ \\
UK Born & $6(19 \%)$ \\
Born in South Asia/Former USSR/Sub-Saharan Africa & $14(45 \%) / 6(19 \%) / 5(16 \%)$ \\
Time in prison & $4(13 \%)$ \\
HIV +ve & $2(6 \%)$ \\
Extensively drug resistant tuberculosis & $3(9 \%)$ \\
Previous or current TB treatment at diagnosis & $11(35 \%)$ \\
MDR-TB Contact & $6(19 \%)$ \\
Homelessness & $2(6 \%)$ \\
Renal disease & $2(6 \%)$ \\
\hline
\end{tabular}

